\title{
A Better Prescription: Advice for a National Strategy on Pharmaceutical Policy in Canada
}

\section{Une meilleure ordonnance : conseils pour une stratégie canadienne nationale relative aux produits pharmaceutiques}

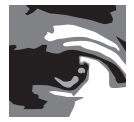 \\ STEVEN G. MORGAN, PHD \\ Professor, School of Population and Public Health \\ University of British Columbia \\ Vancouver, BC \\ MARC-ANDRÉ GAGNON, PHD \\ Associate Professor, School of Public Policy and Administration \\ Carleton University \\ Ottawa, ON
}

BARBARA MINTZES, PHD

Senior Lecturer, Faculty of Pharmacy

University of Sydney

Sydney, Australia

JOEL LEXCHIN, MSC, MD

Professor, Faculty of Health

York University

Toronto, ON

\begin{abstract}
Canada needs a national strategy to fulfill its obligation to ensure universal access to necessary healthcare, including prescription drugs. A 2004 attempt at a national strategy for pharmaceutical policy failed because it lacked clear vision, logical planning and commitment from federal and provincial governments. The result of uncoordinated pharmaceutical policies in Canada has been more than a decade of poor system performance. In this essay, we present a framework for a renewed national strategy for pharmaceutical policy. Building on published research and international frameworks, we propose that pharmaceutical policies of federal, provincial and territorial
\end{abstract}


governments be coordinated around a core health-focused goal. We strongly suggest policy actions be taken on four core objectives that are necessary to support the overarching health goal. If implemented, the proposed strategy would offer clear benefits to all Canadians who use medicines, federal and provincial governments and to the economy as a whole. We therefore argue that political leadership is now needed to articulate and implement such a plan on behalf of Canadians.

\section{Résumé}

Le Canada doit se doter d'une stratégie nationale afin de respecter son obligation d'assurer un accès universel aux services de santé nécessaires, notamment les médicaments sur ordonnance. La tentative de 2004 en ce sens a connu l'échec en raison d'un manque de vision claire, de planification logique et d'engagement de la part des gouvernements provinciaux et fédéral. Le manque de coordination des politiques relatives aux produits pharmaceutiques au Canada a donné lieu à plus d'une décennie de faible rendement pour le système. Dans cet essai, nous proposons un cadre de travail pour le renouvellement de la stratégie nationale relative aux produits pharmaceutiques. À la lumière de recherches publiées et de cadres de travail internationaux, nous proposons que les politiques des gouvernements provinciaux, territoriaux et fédéral sarticulent autour d'un objectif de santé commun. Nous suggérons fortement que l'action politique porte sur quatre objectifs clés, nécessaires pour appuyer l'objectif de santé commun. Si elle était mise en œuvre, la stratégie proposée se traduirait par de réels avantages pour les Canadiens qui prennent des médicaments, pour les gouvernements provinciaux et fédéral ainsi que pour l'ensemble de l'économie du pays. Nous affirmons donc, pour le bien-être des Canadiens, qu'il est temps de mettre en place le leadership politique nécessaire pour articuler et mettre en œuvre un tel plan.

\section{Introduction}

Canada needs a national strategy for pharmaceutical policy and now is the time to make it happen owing to the current alignment of government interests at federal and provincial levels. Since 2010, provinces have been voluntarily collaborating on prescription drug pricing through a Pan-Canadian Pharmaceutical Alliance; and some provinces, most notably Ontario, have been calling for federal-provincial collaboration to establish a universal pharmacare program to make medicines more accessible to all Canadians (Hepburn 2016; Hoskins 2014; Lynas 2010). At the federal level, the Liberals' 2015 election platform included promises to negotiate a new health accord and to work to make prescription drugs more affordable in Canada, promises that ended up in the new health minister's mandate letter after the Liberals formed government in late 2015 (Canada 2015; Liberal Party of Canada 2015). Perhaps not surprisingly then, in January 2016, when the federal, provincial and territorial health ministers met for the first time in many years, they created a working group to explore pharmaceutical policies aimed at reducing prices, at improving prescribing and the appropriate use of drugs, and at improving coverage and access to medicines for Canadians (Canada 2016). 
The World Health Organization (WHO) has long recommended that countries coordinate their pharmaceutical policies to meet their obligation to provide universal access to safe, affordable and appropriately prescribed medicines (Bigdeli et al. 2014; WHO 1988, 2001). The WHO and others have argued that such goals can only be achieved in an equitable and sustainable way through the coordination of many policies that affect the pharmaceutical sector (Australia 1999; Bigdeli et al. 2014; Morgan et al. 2009; WHO 2001).

The case for a coordinated pharmaceutical strategy is particularly strong in Canada, where policies critically important for managing pharmaceuticals are controlled by different levels of government. Canadian provinces hold primary responsibility for healthcare delivery, educating and licensing health professionals, and coverage of pharmaceuticals. Few of these provincial policies are coordinated, either through agreements between provinces or through agreements between provinces and the federal government. As a result of this lack of coordination - and, arguably, as a result of the significant differences in the size and wealth of provinces - the accessibility, use and cost of medicines varies considerably across Canada (Daw and Morgan 2012; Morgan et al. 2013).

The federal government in Canada holds limited responsibility for drug coverage - it provides drug coverage for select populations that account for just $2 \%$ of total prescription drug costs in Canada (CIHI 2015). But the federal government holds primary responsibility for regulating pharmaceutical products, regulating pharmaceutical marketing and setting intellectual property rights and related policies. Because such policies affect the availability, price and use of medicines, those federal policies have been a source of friction with the provinces, which bear most of the resulting costs (Anis 2000).

It is notable that, starting with the Royal Commission on Health Services in 1964, national commissions in Canada have consistently recommended reforms to better coordinate pharmaceutical policies and to better integrate them with other components of the healthcare system (Canada 1964, 1997, 2002a). The Romanow Commission of 2002 recommended that all governments in Canada work together to integrate medically necessary prescription drugs with the Canada Health Act - thereby creating national standards for universal access to necessary medicines (Canada 2002b). Romanow also specifically recommended that a National Drug Agency be created to coordinate a wide range of pharmaceutical policies, including evaluating new drugs, negotiating drug prices and coverage decisions, monitoring of drug safety and electiveness, and providing information to patients and healthcare providers ("We Need Romanow's National Drug Agency" 2003).

Shortly after the Romanow Commission, as part of the 2004 Health Accord, the federal, provincial and territorial governments agreed to try coordinating pharmaceutical policies through a National Pharmaceuticals Strategy (Canada 2004). Some promising reforms were launched in the years that followed, but the strategy ultimately failed. As early as 2009, the Health Council of Canada declared the 2004 strategy a lost opportunity for much-needed federal and provincial cooperation - noting that, while federal and provincial governments could reform pharmaceutical policies in isolation "... there are [policy] interdependencies and limitations to what individual jurisdictions can achieve on their own" (Health Council of Canada 2009b). 
The 2004 strategy arguably failed because it lacked a clear vision and plan that governments were committed to work toward. From the outset, there wasn't a shared understanding of what the pharmaceutical policies of federal, provincial and territorial governments were ultimately striving for on behalf of Canadians. Without a clear vision or goal around which to build the strategy, the list of nine priority elements identified in the 2004 strategy lacked a coherent structure and overarching purpose; moreover, several of the core elements of the 2004 strategy amounted to little more than studying policy problems with few, if any, measurable objectives against which governments' actions (or inactions) could be evaluated. Consistent with the notion that there was little shared vision and commitment, the then federal health minister, Leona Aglukkaq, testified before a 2011 Senate committee that the National Pharmaceuticals Strategy was essentially suspended because "... in order to have a national plan there had to be a national agreement. There was not always consensus around what that would look like" (Canada 2011). The Health Council of Canada attributed part of the lack of shared vision to the changes in government that occurred shortly after the 2004 Health Accord and to the significant disagreement between levels of government regarding the commitment of resources necessary to coordinate and implement critical policy reforms (Health Council of Canada 2009a).

The result of uncoordinated pharmaceutical policies in Canada has been more than a decade of poor system performance. There are examples of promising initiatives and collaborations - such as the establishment of the Pan-Canadian Pharmaceutical Alliance and the CIHR Drug Safety and Effectiveness Network - but, on the whole, and on the basis of the experiences of the entire population (rather than select populations covered by targeted policies), our system lags behind international best practices. Relative to comparable countries, Canadian patients in most provinces face the most significant financial barriers to filling prescriptions, the highest annual burden of out-of-pocket drug costs, and the least frequent prescriber-use of error-reducing drug information systems and e-prescribing tools (Morgan et al. 2013; Schoen et al. 2012). Canada's system is also one of the most expensive systems in the world, resulting in per capita pharmaceutical expenditures that are higher than all other Organisation for Economic Co-operation and Development (OECD) countries with the exception of the US (Gagnon 2014; OECD 2014). Paradoxically (given our high level of pharmaceutical spending), Canada attracts the lowest amounts of pharmaceutical research among comparable countries (OECD 2012; PMPRB 2014).

Governments in Canada should strive for better outcomes for their citizens - and many international comparators show that they could achieve better outcomes. Pharmaceutical policies in the UK, for example, achieve better access to medicines, lower burdens on patients, more frequent use of electronic prescribing assistance tools and far lower total pharmaceutical spending (Morgan et al. 2013). Yet, the UK attracts five times as much pharmaceutical research and development on a per capita basis than Canada does (OECD 2012) - indicating that effective pharmaceutical policies are not a threat to local research investment. 
In this essay, we present a framework for a renewed national strategy for pharmaceutical policy in Canada. We developed this framework through a multi-year process that included reviewing research literature and policy frameworks developed by Canadian policy makers, by the WHO and by other countries; doing two pan-Canadian surveys of policy makers (in 2009 and 2014); and holding workshops of the Pharmaceutical Policy Research Collaboration, a national team of university-based experts in pharmaceutical policy. On the basis of that work, we propose that a pharmaceutical strategy in Canada be designed in a manner consistent with WHO guidance and international best practices. We recommend that governments commit to a pharmaceutical strategy that explicitly aims to improve the performance of the overall Canadian health system and, thus, to improve the health of Canadians by achieving four, inter-related objectives: universal access to necessary medicines; appropriate prescribing and use of medicines; value for money spent on medicines; and patient safety.

The importance of strategic policy action on the objective of access to medicines has been delineated elsewhere (Morgan et al. 2015). In this essay, we provide a broader view of a renewed pharmaceutical strategy in Canada. This includes "pharmacare" reforms that provide universal, equitable access to medicines as well as a wide variety of other policy initiatives that will shape access to medicines and other key dimensions of the performance of the pharmaceutical component of Canada's healthcare system. If implemented, this strategy would offer clear benefits to all Canadians who use medicines, their governments and to the economy as a whole.

\section{A Clear Vision and Plan}

Achieving high performance in pharmaceutical policy requires focus on clear goals and objectives, awareness of policy instruments and options, and understanding of the roles and interactions of different policy actors (Morgan et al. 2009). The starting place in this is a shared vision of the aspirations and priorities we have for public policy in the pharmaceutical sector. Without a vision, we cannot create a strategy - the very definition of which is "... a careful plan or method for achieving a particular goal” (Merriam-Webster 2016).

According to the WHO, the overarching goals of a national pharmaceutical strategy should always be consistent with the country's broader health objectives (WHO 2001). Our proposed goal for Canada's strategy, therefore, is that pharmaceutical policies of federal, provincial and territorial governments should be coordinated in ways that "equitably and sustainably promote the health of Canadians."

Stating that a national strategy for pharmaceutical policies should be dedicated to promoting a healthier nation may seem obvious, but it is necessary and will be transformative if governments across Canada commit to it. It is necessary because, despite being advertised and sold in ways that may make them appear to be consumer goods, pharmaceuticals are actually potent but important inputs to formal healthcare. Prescription drugs, in particular, are inextricably tied to the use of other healthcare services by way of their prescription-only status. 
It therefore follows that pharmaceutical polices ought to be coordinated in ways that, first and foremost, support the goals of the broader healthcare system in which they are situated.

A health-focused vision is transformative because it establishes clear goals for all governments to strive for when making pharmaceutical policy: equitable and sustainable improvements in the health of Canadians. Such a health-centred focus requires that policy makers, healthcare providers and even the general public see investments in pharmaceuticals - particularly public investments in pharmaceuticals - in the context of the broader determinants of health, both for individual patients and for the population as a whole. This frame of reference will help all relevant actors to identify when medicines are the best approach to improving health and when other investments would yield greater value. It should also help focus pharmaceutical policy development, coordination, implementation and evaluation on measurable health-related goals rather than surrogate measures of system performance - such as the speed of regulatory approval times or the numbers of medications on a formulary. An explicitly health-focused national pharmaceutical strategy may be particularly transformative in Canada, where the management of pharmaceuticals used in the community setting - which account for $90 \%$ of the pharmaceutical market in Canada - has not, yet, been fully incorporated into the management of the rest of the public healthcare system.

A clear health-focused vision will also help balance conflicts with secondary policy goals in the pharmaceutical sector. For example, a health focus will dictate strong national policies on drug pricing and affordable access to medicines in an era where trade agreements often provide pharmaceutical manufacturers greater market power (Lopert and Gleeson 2013). Resolving conflicts between different policy objectives does not disregard economic development in the pharmaceutical sector; but it does imply such objectives should not be pursued at the expense of public health and patient safety.

\section{Specific Objectives and Strategic Actions}

Our guiding, health-centred vision provides an important touchstone, but further objectives must be delineated if coordinated policy actions are to be selected, implemented and monitored. Policy frameworks developed by the WHO and others suggest that Canada should focus on four core objectives related to the overarching health-centred vision: (1) universal access to necessary medicines; (2) appropriate prescribing and use of medicines; (3) value for money spent on medicines; and (4) patient safety (Australia 1999; Bigdeli et al. 2014; Morgan et al. 2009; WHO 2001).

As shown in Figure 1 and Table 1, and described in the sections that follow, we propose strategic policy actions that would help Canada to achieve each of the four core objectives of the national strategy. Finally, also drawing on WHO guidance, we propose, as an overarching governance principle, that pharmaceutical policies be made and implemented in a transparent fashion, based on routinely collected and reported data on system performance (Bigdeli et al. 2014; WHO 2001). 
FIGURE 1. A renewed strategy for pharmaceutical policy, guided by a clear and compelling vision with supporting policy objectives and actions

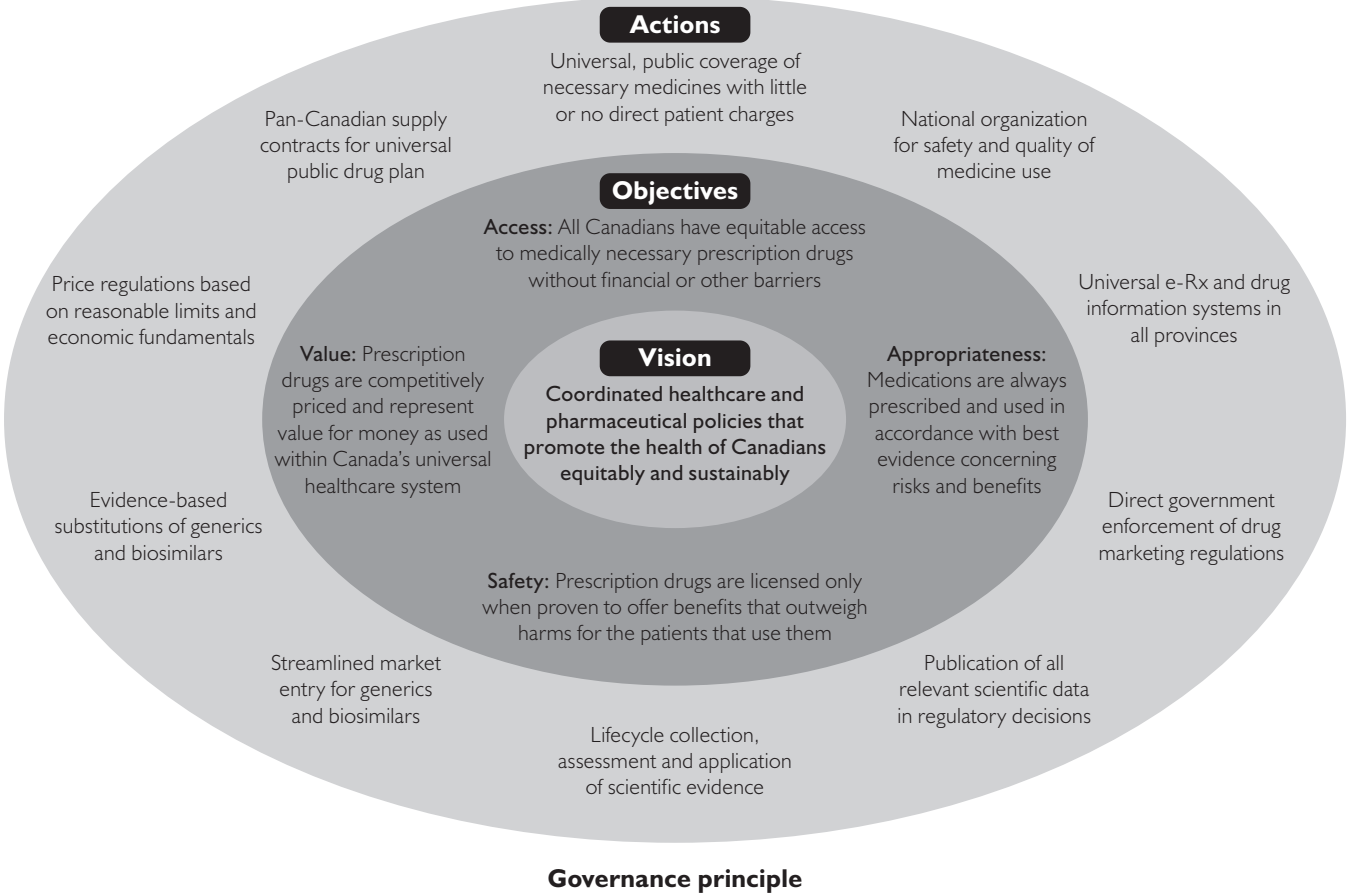

Pharmaceutical policies should be made and implemented in a transparent fashion, based on routinely collected and reported data on system performance, by decision-makers who are accountable to the public

\section{Access}

The Canada Health Act ensures all Canadians have access to medically necessary physicians' services and hospital care - including all prescription drugs used in hospital - through universal, comprehensive, public health insurance. This system of universal health coverage in Canada does not extend to medications used in the community. Outside of hospitals, prescription drugs are financed by an incomplete patchwork of public and private drug plans that leaves approximately $10 \%$ of Canadians with no prescription drug coverage at all and a further $11 \%$ with limited drug coverage, requiring them to pay for most of their prescription drug costs out-ofpocket (Angus Reid Institute 2015; Barnes and Anderson 2015; Daw and Morgan 2012).

The absence of universal coverage of necessary medicines creates significant access problems. In July 2015, a national survey found that 14\% of Canadians reported that they or members of their household didn't fill a prescription in the past year because of cost. A further 9\% either didn't renew a prescription or skipped doses to make prescriptions last longer because of cost (Angus Reid Institute 2015). Though there are regional variations in the rates of cost-related non-adherence to medications - from 19\% in Quebec and Manitoba to $29 \%$ in British Columbia - international surveys suggest that all provinces in Canada experience these problems at rates greater than comparable health systems in Europe and Australasia (Morgan et al. 2013; Osborn et al. 2014). Research suggests the problem stems 
from inadequate drug coverage, regardless of income level (Law et al. 2012). Lack of access because of inadequate insurance is associated with significant adverse health outcomes, including premature death (Booth et al. 2012; Kesselheim et al. 2015).

TABLE 1. Details concerning suggested elements of a renewed strategy for pharmaceutical policy in Canada

Guiding vision: Coordinated federal, provincial and territorial pharmaceutical policies that work with other healthcare policies to promote equitable and sustainable improvements in the health of Canadians

\begin{tabular}{|c|c|c|}
\hline Policy objectives & Strategic policy actions & Policy actors \\
\hline $\begin{array}{l}\text { Access: All Canadians } \\
\text { have equitable access } \\
\text { to medically necessary } \\
\text { prescription drugs } \\
\text { without financial } \\
\text { or other barriers }\end{array}$ & $\begin{array}{l}\text { - Universal, public coverage of medically necessary } \\
\text { prescription drugs by } 2020 \\
\text { - Fair, transparent and evidence-based system of determining } \\
\text { which drugs are covered under a universal drug plan } \\
\text { - Coordinated procurement policies as per value } \\
\text { objective of renewed National Pharmaceuticals Strategy }\end{array}$ & $\begin{array}{l}\text { - Provinces as administrators } \\
\text { - } \text { national standards } \\
\text { - Relevant agencies (e.g., Canadian Agency } \\
\text { for Drugs and Technologies in Health) }\end{array}$ \\
\hline $\begin{array}{l}\text { Appropriateness: } \\
\text { Medications are } \\
\text { always prescribed and } \\
\text { used in accordance } \\
\text { with best evidence } \\
\text { concerning risks } \\
\text { and benefits }\end{array}$ & $\begin{array}{l}\text { - Government to take direct responsibility for enforcing } \\
\text { regulations concerning the promotion of medicines } \\
\text { - Completion of population-based electronic prescribing } \\
\text { and drug-information systems in all provinces by } 2020 \\
\text { - Establish or designate a national organization to } \\
\text { coordinate initiatives regarding quality of medicine use }\end{array}$ & $\begin{array}{l}\text { - Health Canada for regulatory enforcement } \\
\text { - Canada Health Infoway and provincial } \\
\text { and federal governments for electronic } \\
\text { prescribing and information systems } \\
\text { - New national agency or mandate } \\
\text { expansion for existing agency for } \\
\text { coordination of initiatives }\end{array}$ \\
\hline $\begin{array}{l}\text { Value: Prescription } \\
\text { drugs are competitively } \\
\text { priced and represent } \\
\text { value for money as } \\
\text { used within Canada's } \\
\text { universal healthcare } \\
\text { system }\end{array}$ & $\begin{array}{l}\text { - Pan-Canadian price and supply contracts for patented } \\
\text { drugs covered under the universal public drug plan } \\
\text { - Streamline market entry for generics and biosimilars } \\
\text { - Modernization of pharmaceutical price regulations to } \\
\text { include non-patented medicines and reasonable price } \\
\text { limits based on economic fundamentals }\end{array}$ & $\begin{array}{l}\text { - Arm's-length agency for supply contracts, } \\
\text { with representation of patients, health } \\
\text { professionals and governments } \\
\text { - Federal government for streamlining generic } \\
\text { and biosimilar entry } \\
\text { - Regulatory and mandate changes for } \\
\text { Patented Medicine Prices Review Board }\end{array}$ \\
\hline $\begin{array}{l}\text { Safety: Prescription } \\
\text { drugs are only licensed } \\
\text { when proven to offer } \\
\text { benefits that outweigh } \\
\text { harms for the patients } \\
\text { that use them }\end{array}$ & $\begin{array}{l}\text { - Publication of all relevant scientific data concerning both } \\
\text { - Lositive and negative regulatory decisions } \\
\text { and application of scientific evidence }\end{array}$ & $\begin{array}{l}\text { - Health Canada for regulatory policy } \\
\text { and transparency } \\
\text { - Provincial governments for collecting } \\
\text { and making available real-world data } \\
\text { - Federal government for enabling timely } \\
\text { analysis and publication of real-world data }\end{array}$ \\
\hline
\end{tabular}

To ensure universal access to necessary medicines, several national commissions on healthcare in Canada have recommended that federal, provincial and territorial governments implement a universal, public drug plan that brings medically necessary prescription drugs into Canada's single-payer healthcare system (Canada 1964, 1997, 2002a). In 2015, a universal "pharmacare" system involving little or no direct charges to patients (to ensure covered prescriptions are accessible without financial barriers); a national formulary (to achieve equitable, evidence-based coverage across provinces); and a transparent, pre-defined budget (to ensure sustainability and efficiency vis-à-vis other investments in healthcare) was endorsed by over 280 university-affiliated experts in healthcare policy and clinical practice from across Canada (Morgan et al. 2015).

Not every medication should be covered under such a universal pharmacare plan in Canada - nor is every medication covered under comparable systems worldwide. Reasonable limits need to be set - and they should be set through transparent, publicly 
accountable coverage decision-making processes. However, if the selection of medications to be covered under such a program is guided by public health goals and the best available evidence, a universal pharmacare system will not only contribute to the access objective of a national pharmaceutical strategy, it could also contribute to other core objectives, including appropriateness and value for money.

In a manner similar to contributions toward the cost of provincial health insurance programs for medical and hospital care, federal contributions to the cost of universal pharmacare could help all provinces to afford to participate and to ensure that all provinces provide coverage that meets national standards (Morgan et al. 2015). Although such a pharmacare program would change both the federal-provincial and private-public mixes of prescription drug financing in Canada, research has shown that a universal public drug plan could reduce total prescription drug costs by billions of dollars per year (Gagnon 2014; Gagnon and Hebert 2010; Morgan, Law et al. 2015).

\section{Appropriateness}

There is good evidence that the quality of medicine use in Canada could be improved. In 2013, more than one in three Canadians (37\%) over age 65 filled at least one prescription for medicines believed to pose unnecessary risks for older adults - at a total direct cost of over $\$ 400$ million for prescriptions alone (Morgan et al. In Press). Such prescribing has negative impacts on patient health and health system demands. It is estimated that one in six hospitalizations in Canada could be prevented if prescription drugs were prescribed and used more appropriately (Samoy et al. 2006).

There are many causes of inappropriate medication use, including too much reliance on information from drug companies, pressure to prescribe from patients and peers and cultural expectations that may bias assessments of the risk and benefits of treatments (Cullinan et al. 2014; Hoffmann and Del Mar 2015; Mintzes et al. 2013; Spurling et al. 2010). Strategies to address inappropriate medication use therefore need to be multi-faceted and coordinated to respond to all those factors. They also need to be sustained over time (Sketris et al. 2009).

Canadian efforts to improve the quality of prescribing have historically been fragmented, but show growing potential for a coordinated national effort. A number of promising initiatives promoting appropriate prescribing have been led by provinces, some with shared support through national agencies (Sketris et al. 2009). Physician leaders are also taking action through a Canadian chapter of the Choosing Wisely initiative to inform doctors and patients about overuse of certain prescription drugs and diagnostic tests (Levinson and Huynh 2014). Further, Canada Health Infoway has helped provinces develop infrastructure for prescription monitoring and surveillance and the federal government has funded work to develop a national strategy on prescription drug abuse (Smolina et al. 2016).

More can be done to improve prescribing appropriateness through a coordinated national strategy. At the federal level, Health Canada could better limit unwanted effects of commercial marketing activities by taking more direct responsibility for enforcing existing regulations 
concerning the promotion of medicines to patients and to professionals, ending self-regulation by industry (Lexchin and Mintzes 2014). Similarly, more stringent rules on conflicts of interest at Canadian teaching hospitals and universities would help to ensure future health professionals are trained based on best available evidence rather than commercial influences (Rochon et al. 2010; Shnier et al. 2013); further, legislated disclosure of financial ties between health professionals and the pharmaceutical industry, as is now done in the US, would increase transparency and help to mitigate the effects of conflicts of interest of practicing health professionals (Boozary and Lexchin 2014). Taking such actions at a federal level would protect institutions - and, indeed, provinces - from the threat of investment-related repercussions should they enact such policies at a local level. Though such threats would not necessarily be credible, they can place significant pressures on local decision-makers and thereby limit regional actions to address known pharmaceutical policy problems (Morgan and Cunningham 2008).

At the provincial level, governments can improve patient and professional education and engagement in matters related to quality of medication use. To provide foundational support for the monitoring and evaluation of prescribing practices and outcomes, all provinces should commit to timely completion of population-based electronic prescribing and drug information systems. Such systems can be used to alert pharmacies to potential interactions between different prescriptions for the same patient and to notify authorities of problematic and potentially fraudulent medication use; furthermore, if well designed, such systems can also be used to provide real-time clinical decision support, including flagging potential dosing errors and providing evidence-based, point-of-care treatment recommendations (Smolina et al. 2016).

Collaborations between provinces and the federal government on prescribing appropriateness will require administrative and operational support. This will likely require a new national agency - or an expanded mandate of an existing agency - to coordinate quality improvement initiatives. The role of NPS MedicineWise within Australia's national strategy for quality use of medicines is one example of how a national agency can help ensure that quality improvement initiatives can be developed, implemented and evaluated across a diverse federation (Australia 2002; NPS MedicineWise 2015). All regions in Canada would benefit from a dedicated agency that pooled capacity to mount and evaluate quality-improvement campaigns - even if such campaigns are to be delivered by provinces and territories.

\section{Value}

A system to provide equitable access to necessary healthcare - including prescription drugs - must be designed to be financially sustainable; otherwise, health-related goals will not be achieved in an equitable and ongoing way. Given that Canadians will spend approximately $\$ 30$ billion on prescription drugs in 2016, it is important to ensure that medicines are priced competitively and only used when they represent value for money relative to other means of promoting the health of patients and the population as a whole. Unfortunately, Canada's current approach to managing pharmaceutical expenditures is fragmented across jurisdictions and between public and private sectors in ways that limit our capacity to control prices and encourage cost-effective medication use. 
At every level, current and past efforts to control the cost of pharmaceuticals in Canada have been hampered by fractured jurisdiction and lack of coordination. The federal government regulates only patented drug prices, and only on the basis of comparisons to official "list" prices of medications in a handful of other countries. Provinces, minus Quebec, have been negotiating drug pricing collectively through the Pan-Canadian Pharmaceutical Alliance since 2010, and Quebec and the federal government have recently joined those negotiations. However, even when all governments participate in a negotiation, it applies only to public drug plan purchases - which cover less than $50 \%$ of prescription drug expenditures in every province (CIHI 2015) - and only in the jurisdictions that actually implement the negotiated agreement. That limits governments' bargaining power and the extent to which negotiated prices apply, as uninsured patients are powerless to negotiate better prices from suppliers and even private insurers are ill-equipped to manage pharmaceutical costs (Gagnon 2014).

Although many Canadians have private drug coverage, the insurance companies offering those plans lack the financial incentives, negotiating capacity, and clinical authority necessary to effectively control prices and manage the allocation of expenditures across competing demands for healthcare. Not only are private insurers isolated from the management of the rest of the healthcare system - and thereby in a limited position to weigh the total costs and benefits of use of medicines vis-à-vis other healthcare services - they are also providing an insurance product that is most commonly purchased as part of complex labour negotiations in which the perceived generosity of the coverage is critical ( $\mathrm{O}^{\prime} \mathrm{Brady}$ et al. 2015). These characteristics of private drug insurance (in the context of Canada's public healthcare system) result in extraordinary waste: private sector analysts estimate approximately $\$ 5$ billion per year spent by employers on drug benefits is wasted because private drug plans are not well-positioned to manage drug prices, cost-effectiveness, or the prescribing and dispensing decisions of Canadian health professionals (Express Scripts Canada 2015).

Unfortunately, governments cannot simply step in to help uninsured patients or private insurers to obtain better prices without including them within the publicly managed drug coverage system and related price negotiations. The primary reason for this is that negotiated drug prices are now routinely kept secret in the modern pharmaceutical market because so many nations - including Canada - have historically regulated drug prices based on what manufacturers charge in other countries (Docteur et al. 2008; Seiter 2010; Vogler et al. 2015). In response to this practice, brand-name pharmaceutical manufacturers now artificially inflate the list prices of their medicines worldwide; then, instead of giving every country the same price reductions offered to those with effective negotiating power, pharmaceutical manufacturers now simply do price deals in secret with individual countries (Morgan et al. 2013b). This means that governments in Canada cannot simply lower the publicly available price paid by everyone in the country - including private insurers - because manufacturers would then have to give that lower price to countries around the world.

The net effect of Canada's fragmented pricing and expenditure management policies is higher total spending on pharmaceuticals than any comparable country with a universal 
A Better Prescription: Advice for a National Strategy on Pharmaceutical Policy in Canada

healthcare system (OECD 2014). Significant improvements could be made by aligning coverage of medically necessary prescription drugs with Canada's universal, public healthcare system to consolidate purchasing power and to provide providers, managers and citizens with better incentives to carefully weigh the benefits and costs of pharmaceutical and non-pharmaceutical treatment options.

It is simple economic logic that purchasing power would be maximized through the creation of a pan-Canadian single-payer system for medications selected for universal coverage. Such a system would both provide sizeable and predictable rewards to manufacturers who price competitively and protect patients from paying list prices inflated by the worldwide practice of secret price rebates. It is also simple economic logic that a program integrated with the management of medicare - including the collection and analysis of linked health data sets - would improve the capacity of all provinces and territories to employ evidence-based risk sharing policies. These policies could set rebates on drug prices according to the rate and appropriateness of the use of the medicine under the drug plan and, in some cases, according to the actual impacts of the drug on patient health outcomes (Morgan et al. 2013a).

Whereas confidential rebates are needed to obtain competitive prices for patented medicines in today's global pharmaceutical market, more transparent tools are needed to secure better generic drug prices. The process by which generic manufacturers currently gain access to the Canadian market involves uncertainties - and costs - not faced in comparable markets (Grootendorst et al. 2012). A pharmaceutical strategy that included a commitment to streamline market entry by removing unnecessary barriers to generic entry would improve market access for generic competitors and thereby increase the effectiveness of other policies designed to obtain a more competitively priced and secure supply of generic drugs in Canada.

Once on the market, generics are currently priced in ways that allow retail pharmacies to collect sizable rebates from generic manufacturers without passing those rebates on to payers (Competition Bureau 2007; Law and Kratzer 2013). These secret rebates for generic drugs do not benefit patients, government drug plans or private drug plans. In contrast, competitive tendering processes under a universal drug plan would achieve much more transparent, competitive prices for the public system - with estimated savings on the order of $50 \%$ or more of current generic drug prices (Beall et al. 2014; Gagnon 2014; Law and Morgan 2011; Morgan et al. 2007). Supply contracts for generic drugs can even be designed to limit the risk of drug shortages and sudden price increases (Gagnon 2012; Gagnon 2016; Morgan 2013a).

With patents now expiring on many high-cost biologic drugs, similar evidence-based licensing, purchasing and reimbursement policies should be applied to biosimilars - competing versions of off-patent biologic drugs (Renwick et al. 2016).

Finally, despite the importance of negotiated contracts as a means of controlling prices, recent cases of extraordinary pricing of both patented and non-patented drugs suggest that regulatory policies may still be needed to prevent abuse of market power in the pharmaceutical sector (Bach 2015; Carrier and Kesselheim 2015). To this end, a renewed national strategy for pharmaceuticals should include a commitment to modernize Canada's price regulations, 
which should apply to patented and non-patented medicines alike. It will be important for Canada to work with other countries to establish regulations on drug prices that are grounded in economic and ethical fundamentals concerning the balance between consumer protection and investor rights, access to medicines and incentives for innovation (Bach 2015; Vogler et al. 2015).

\section{Safety}

Efforts to ensure new medicines generate greater benefits than harms for patients mean that all medications are subject to regulatory review before they come to market and monitoring afterwards. This work is of paramount importance to public health because, while patients suffer if they cannot get effective treatments, patients who experience unwanted side effects of medicines also suffer, sometimes irreversibly, from harms that medications can cause. Biological factors ultimately drive the effects of drugs on patients; however, measurable policy process factors - including regulatory rigour, scientific transparency, and outcomes monitoring - all work to minimize harms.

Unfortunately, there is evidence to suggest that Health Canada may currently be erring too much on the side of expedited access to medicines of promising but unproven potential to safely and effectively improve patient health. Out of 345 new active substances that were approved between 1997 and 2012 and evaluated for their therapeutic benefits by independent organizations, 91 were given priority reviews. Only 52 of them, however, were judged to be therapeutically innovative (Lexchin 2015). In addition to this tendency to grant priority reviews to many drugs that are comparable to others on market, drugs having received a priority review in Canada have a $34 \%$ chance of acquiring a serious safety warning compared to just under $20 \%$ for those given standard reviews (Lexchin 2012).

The federal government has made some improvements in regulation with the passage of the Protecting Canadians from Unsafe Drugs Act, known as Vanessa's Law. This law gives the government a number of powers Canadians likely thought it already had: i.e., the power to initiate mandatory recalls of unsafe drugs, to compel manufacturers (and others) to provide safety information, to impose conditions on market authorizations and to compel companies to revise labels to clearly reflect health risk information (Herder et al. 2014; Hohl et al. 2015). Despite these improvements, more needs to be done.

A national strategy that included commitments to routinely collect, assess and publish scientific information about drug safety and effectiveness throughout the lifecycle of pharmaceutical products would provide critical information to regulators, healthcare providers and patients. This commitment to transparency would begin even before drugs come to market, as exemplified by the European Medicines Agency, which makes all clinical trial data publicly available (Bonini et al. 2014). Greater transparency can even help manufacturers because access to de-identified data from trials can help all manufacturers to increase the efficiency of drug development by reducing unnecessary duplication of efforts (Eichler et al. 2013). Moreover, greater communication about clinical trials - even before they are conducted - can help to design trials that meet not only the regulator's information needs but also those of 
clinicians, patients, and managers of the healthcare system who ultimately determine how quickly and often new products are used in clinical practice (Backhouse et al. 2011).

Because the needs for scientific rigour and transparency continue over the life course of a medicine, a national strategy for pharmaceutical policy in Canada should include commitments from federal and provincial governments to monitor the use and safety of all prescription drugs on the market (Lemmens and Gibson 2014). No one jurisdiction in Canada has the population size and technical capacity to effectively monitor all of the potentially important indicators of drug safety and effectiveness. Thus, a national strategy is needed, whether through a centralized repository or distributed data analysis network - such as the Drug Safety and Effectiveness Network of the Canadian Institutes of Health Research. Commitment to these safety measures is needed because the quality of the science relies on the quality of the drug and linked health data collected and made accessible for analysis. To ensure valuable information is generated from the data in a timely and appropriate manner, the federal government could assist provinces to complete the implementation of required data infrastructure, standardize data systems for meaningful secondary uses and develop the scientific capacity needed for a pan-Canadian approach to drug safety surveillance.

\section{Governance}

The final ingredient for effective national pharmaceutical policies is good governance. The form of governance required begins with buy-in. Though many national and international reports and commissions have recommended that Canada strive for a system that provides universal access to safe, affordable and appropriately prescribed medicines, failure by federal, provincial and territorial governments to clearly commit to those goals has resulted in poor pharmaceutical policy performance in Canada.

It is important to note that the failure of federal and provincial governments to agree to clear goals for pharmaceutical policies does not necessarily imply that the majority of Canadians would not agree to a clear set of goals and objectives for such a system. Students of healthcare policy in Canada will know that different levels of government in Canada occasionally cling to notions of jurisdictional autonomy and independence, which can impede the development of a national strategy in this sector - despite the potentially significant benefits of a strategy for Canadians in every region of the country.

Thus, whether through the new federal, provincial and territorial working group, or through another mechanism, Canada's policy makers can take the first step to good governance in pharmaceutical policy by identifying and committing to a clear vision and set of logically related policy goals for federal, provincial and territorial policies in this sector. Governments must develop and commit to their own vision and plan if a strategy is truly going to be transformative. And they will need to do so with input - throughout the process - from key stakeholders, including the Canadian public, health professionals and health system managers. We believe that the model presented in this essay is a good place to start related deliberations and consultations. 
Once a vision for a country's pharmaceutical strategy is identified, the WHO recommends that governments commit to transparency and accountability throughout the policy process, including listening to stakeholders and engaging citizens in its development (Bigdeli et al. 2014; WHO 2001). To do this requires investment in the collection, analysis and publication of data on the performance of pharmaceutical policies - including public opinion data as appropriate. Measuring progress in this way will not only help keep policy makers accountable but also allows for ongoing policy adaptation and improvement. In this way, clarity of the policy vision and measures of accountability creates a virtuous circle: it helps to identify truly strategic actions to be taken, provides compelling grounds for those actions and thereby buttresses policy makers against political pressures to divert from the strategic course. In a federation like Canada's, that collective commitment to a clear, transparent plan may have tremendous advantages in a sector, like this one, where coordinated actions are in the collective interest.

\section{Conclusion}

Royal commissions in Canada have long recognized the need for more coordinated pharmaceutical policies in Canada. The 2004 National Pharmaceuticals Strategy was the first explicit attempt of federal, provincial and territorial governments to do this. Unfortunately, that attempt at coordinating policies failed to be transformative because it lacked clear vision, logical planning and commitment from federal and provincial governments. The result has been continued poor performance of the pharmaceutical component of Canada's healthcare system.

Building on international frameworks for drug policy, we have provided a framework for Canada that could form the basis for a clear, compelling and transformative strategy for coordinated pharmaceutical policy in Canada. The framework uses an overarching public health vision to identify a logical set of interrelated, measurable objectives to be pursued by policy actors throughout the system and across jurisdictions.

With those objectives in mind, we have suggested a variety of strategic policy actions that, if implemented in an integrated fashion, would help meet the objectives of access, appropriateness, value and safety; and, in so doing, they would support the overarching goal of improving the health of Canadians through coordinated pharmaceutical and health policies.

Whether or not one accepts the overarching, health-focused vision of the strategy outlined above, it is clear every government's actions - and inactions - on policies within their jurisdiction will have significant effects on interrelated pharmaceutical sector outcomes and, thus, overall health system performance. With a new health accord in negotiation, the prospect for a new strategy on pharmaceutical policy is high. To make transformative change happen for the better, leaders in federal, provincial and territorial governments will have to delineate a logical framework for coordinated policy action to achieve desirable policy goals and objectives. Moreover, they will need to embrace cooperation, coordination and accountability rather than historical patterns of autonomy and apathy in pharmaceutical policy. Thus, what is needed now is political leadership - at all levels of government - to define and commit to a clear and logical pharmaceutical strategy on behalf of all Canadians. 


\section{Acknowledgements}

This work was supported in part by the Canadian Institutes of Health Research (CIHR)/Health Canada, Emerging Team, Equity in Access to Necessary Medicines. The funding agency had no role in the study or decision to publish. All opinions and conclusions are those of the authors.

Correspondence may be directed to: Steven G. Morgan, Professor, School of Population and Public Health, University of British Columbia, 267 - 2206 East Mall; Vancouver, BC V6T 1Z3; tel.: 604-822-7012; e-mail: steve.morgan@ubc.ca.

\section{References}

Angus Reid Institute. 2015. Prescription Drug Access and Affordability an Issue for Nearly a Quarter of All Canadian Households. Vancouver: Angus Reid Institute.

Anis, A.H. 2000. "Pharmaceutical Policies in Canada: Another Example of Federal-Provincial Discord." Canadian Medical Association Journal 162(4): 523-26.

Australia. 1999. National Medicines Policy 2000. Canberra: Commonwealth Department of Health and Aged Care. Australia. 2002. The National Strategy for Quality Use of Medicines. Canberra: Commonwealth Department of Health and Ageing.

Bach, P.B. 2015. "New Math on Drug Cost-Effectiveness." New England Journal of Medicine 373(19): 1797-99. doi:10.1056/NEJMp1512750.

Backhouse, M.E., M. Wonder, E. Hornby, A. Kilburg, M. Drummond and F.K. Mayer. 2011. "Early Dialogue between the Developers of New Technologies and Pricing and Reimbursement Agencies: A Pilot Study." Value in Health 14(4): 608-15. doi:10.1016/j.jval.2010.11.011.

Barnes, S. and L. Anderson. 2015. Low Earnings, Unfilled Prescriptions: Employer-Provided Health Benefit Coverage in Canada. Toronto: Wellesley Institute.

Beall, R.F., J.W. Nickerson and A. Attaran. 2014. "Pan-Canadian Overpricing of Medicines: A 6-Country Study of Cost Control for Generic Medicines." Open Medicine 8(4): e130.

Bigdeli, M., D.H. Peters and A.K. Wagner (Eds.). 2014. Medicines in Health Systems: Advancing Access, Affordability and Appropriate Use. Geneva, Switzerland: World Health Organization.

Bonini, S., H.G. Eichler, N. Wathion and G. Rasi. 2014. "Transparency and the European Medicines Agency Sharing of Clinical Trial Data." New England Journal of Medicine 371(26): 2452-55. doi:10.1056/NEJMp1409464.

Booth, G.L., P. Bishara, L.L. Lipscombe, B.R. Shah, D.S. Feig, O. Bhattacharyya and A.S. Bierman. 2012. “Universal Drug Coverage and Socioeconomic Disparities in Major Diabetes Outcomes.” Diabetes Care 35(11): 2257-64. doi:10.2337/dc12-0364.

Boozary, A. and J. Lexchin. 2014 (March 26). "Big Pharma's Relationship with Your Doctor Needs Some U.S.-Style Sunshine." The Globe and Mail.

Canada. 1964. Royal Commission on Health Services. Ottawa: Queen's Printer.

Canada. 1997. Canada Health Action: Building on the Legacy. Ottawa: National Forum on Health.

Canada. 2002a. Building on Values: The Future of Health Care in Canada - Final Report (pp. 356). Saskatoon: Commission on the Future of Health Care in Canada.

Canada. 2002b. Chapter 9: Prescription Drugs Building on Values: The Future of Health Care in Canada - Final Report. Saskatoon: Commission on the Future of Health Care in Canada.

Canada. 2004. First Minister's Meeting on the Future of Health Care 2004: A 10-Year Plan to Strengthen Health Care. Retrieved March 13, 2007. <http://www.hc-sc.gc.ca/hcs-sss/delivery-prestation/fptcollab/2004-fmm-rpm/index_e.html>.

Canada. 2011. Standing Senate Committee on Social Affairs, Science and Technology, Study on the Progress in Implementing the 2004 10-Year Plan to Strengthen Health Care, Issue 8 - Evidence Proceedings of the Standing Senate Committee on Social Affairs, Science and Technology. Ottawa: Government of Canada. 
Canada. 2015. Minister of Health Mandate Letter. Retrieved February 19, 2016. <http://pm.gc.ca/eng/ minister-health-mandate-letter>.

Canada. 2016. Statement of the Federal-Provincial-Territorial Ministers of Health. Retrieved February 19, 2016. $<$ http://news.gc.ca/web/article-en.do?nid=1029069>.

Carrier, M. and A. Kesselheim. 2015. "The Daraprim Price Hike and a Role for Antitrust." Health Affairs BLOG. Retrieved May 6, 2016. <http://healthaffairs.org/blog/2015/10/21/the-daraprim-price-hike-and-a-role-for-antitrust/>.

Canadian Institute for Health Information (CIHI). 2015. National Health Expenditure Trends, 1975 to 2015.

Retrieved February 19, 2016. <https://secure.cihi.ca/estore/productSeries.htm?pc=PCC52>.

Competition Bureau. 2007. Generic Drug Sector Study (pp. 66). Ottawa: Competition Bureau Canada.

Cullinan, S., D. O'Mahony, A. Fleming and S. Byrne. 2014. “A Meta-Synthesis of Potentially Inappropriate Prescribing in Older Patients." Drugs \& Aging 31(8): 631-38. doi:10.1007/s40266-014-0190-4.

Daw, J.R. and S.G. Morgan. 2012. "Stitching the Gaps in the Canadian Public Drug Coverage Patchwork? A Review of Provincial Pharmacare Policy Changes from 2000 to 2010." Health Policy 104(1): 19-26. doi:10.1016/j.healthpol.2011.08.015.

Docteur, E., V. Paris and P. Moise. 2008. Pharmaceutical Pricing Policies in a Global Market. Paris: Organisation for Economic Co-operation and Development.

Eichler, H.G., F. Petavy, F. Pignatti and G. Rasi. 2013. “Access to Patient-Level Trial Data-a Boon to Drug Developers." New England Journal of Medicine 369(17): 1577-79. doi:10.1056/NEJMp1310771.

Express Scripts Canada. 2015. 2015 Drug Trend Report. Mississauga: Express Scripts Canada.

Gagnon, M.-A. 2012. "Drug Shortages: Searching for a Cure." Healthcare Policy 7(4): 10-17.

Gagnon, M.-A. 2014. A Roadmap to a Rational Pharmacare Policy in Canada. Ottawa: Canadian Federation of Nurses Unions.

Gagnon, M.-A. 2016. "Informations complémentaires quant au projet de loi 81 (Loi visant à réduire le coût de certains médicaments couverts par le régime général d'assurance médicaments en permettant le recours à une procédure d'appel d'offres)." Submitted to Commission de la santé et des services sociaux.

Gagnon, M.-A. and G. Herbert. 2010. The Economic Case for Universal Pharmacare: Costs and Benefits of Publicly Funded Drug Coverage for all Canadians. Ottawa, ON: Canadian Centre for Policy Alternatives.

Grootendorst, P., R. Bouchard and A. Hollis. 2012. “Canada's Laws on Pharmaceutical Intellectual Property: The Case for Fundamental Reform." Canadian Medical Association Journal 184(5): 543-49. doi:10.1503/cmaj.110493.

Health Council of Canada. 2009a. A Commentary on the National Pharmaceuticals Strategy: A Prescription Unfilled. Toronto, ON: Author.

Health Council of Canada. 2009b. A Status Report on the National Pharmaceuticals Strategy: A Prescription Unfilled. Toronto, ON: Author.

Hepburn, B. 2016 (April 23). “Eric Hoskins' Quiet Campaign for Pharmacare.” Toronto Star. Retrieved May 6, 2016. <http://www.thestar.com/opinion/commentary/2016/04/23/eric-hoskins-quiet-campaign-forpharmacare-hepburn.html>.

Herder, M., E. Gibson, J. Graham, J. Lexchin and B. Mintzes. 2014. "Regulating Prescription Drugs for Patient Safety: Does Bill C-17 Go Far Enough?” Canadian Medical Association Journal 186(8): e287-92. doi:10.1503/cmaj.131850.

Hoffmann, T.C. and C. Del Mar. 2015. "Patients' Expectations of the Benefits and Harms of Treatments, Screening, and Tests: A Systematic Review." JAMA Internal Medicine 175(2): 274-86. doi:10.1001/ jamainternmed.2014.6016.

Hohl, C., J.R. Lexchin and E. Balka. 2015. "Can Reporting of Adverse Drug Reactions Create Safer Systems While Improving Health Data?" Canadian Medical Association Journal 187(11): 789-90. doi:10.1503/cmaj.150057. Hoskins, E. 2014 (October 14). "Why Canada Needs a National Pharmacare Program.” The Globe and Mail. Retrieved May 6, 2016. <http://www.theglobeandmail.com/opinion/why-canada-needs-a-national-pharmacare-program/ article21086014/>.

Kesselheim, A.S., K.F. Huybrechts, N.K. Choudhry, L.A. Fulchino, D.L. Isaman, M.K. Kowal and T.A. Brennan. 2015. "Prescription Drug Insurance Coverage and Patient Health Outcomes: A Systematic Review." American Journal of Public Health 105(2): e17-30. doi:10.2105/AJPH.2014.302240. 
Law, M.R., L. Cheng, I.A. Dhalla, D. Heard and S.G. Morgan. 2012. "The Effect of Cost on Adherence to Prescription Medications in Canada." Canadian Medical Association Journal 184(3): 297-302.

Law, M.R. and J. Kratzer. 2013. “The Road to Competitive Generic Drug Prices in Canada." Canadian Medical Association Journal 185(13): 1141-44. doi:10.1503/cmaj.121367.

Law, M.R. and S.G. Morgan. 2011. "Purchasing Prescription Drugs in Canada: Hang Together or Hang Separately." Healthcare Policy 6(4): 22-26.

Lemmens, T. and S. Gibson. 2014. “Decreasing the Data Deficit: Improving Post-Market Surveillance in Pharmaceutical Regulation". McGill Law Journal 59(4): 943-88.

Levinson, W. and T. Huynh. 2014. “Engaging Physicians and Patients in Conversations about Unnecessary Tests and Procedures: Choosing Wisely Canada." Canadian Medical Association Journal 186(5): 325-26. doi:10.1503/cmaj.131674.

Lexchin, J. 2012. “New Drugs and Safety: What Happened to New Active Substances Approved in Canada between 1995 and 2010?” Archives of Internal Medicine 172(21): 1680-81. doi:10.1001/ archinternmed.2012.4444.

Lexchin, J. 2015. "Health Canada's Use of its Priority Review Process for New Drugs: A Cohort Study." BMJ Open 5: e006816.

Lexchin, J. and B. Mintzes. 2014. "A Compromise Too Far: A Review of Canadian Cases of Direct-toConsumer Advertising Regulation." International Journal of Risk and Safety in Medicine 26(4): 213-25. doi:10.3233/JRS-140635

Liberal Party of Canada. 2015. A New Health Accord. Retrieved February 19, 2016. <https://www.liberal.ca/ realchange/a-new-health-accord/>.

Lopert, R. and D. Gleeson. 2013. “The High Price of 'Free' Trade: U.S. Trade Agreements and Access to Medicines." The Journal of Law, Medicine E Ethics 41(1): 199-223. doi:10.1111/jlme.12014.

Lynas, K. 2010. “New Momentum for a Pan-Canadian Purchasing Alliance for Prescription Drugs." Canadian Pharmacists Journal 143(6): 264-65. doi:10.3821/1913-701x-143.6.264.

Merriam-Webster. 2016. Merriam-Webster: Dictionary and Thesaurus. Retrieved February 19, 2016. <http:// www.merriam-webster.com>.

Mintzes, B., J. Lexchin, J. Sutherland, M.-D. Beaulieu, M. Wilkes, G. Durrieu and E. Reynolds. 2013. "Pharmaceutical Sales Representatives and Patient Safety: A Comparative Prospective Study of Information Quality in Canada, France and the United States." Journal of General Internal Medicine 28(10): 1368-75. doi:10.1007/s11606-013-2411-7.

Morgan, S.G. and C. Cunningham. 2008. “The Effect of Evidence-Based Drug Coverage Policies on Pharmaceutical R\&D: A Case Study from British Columbia - Abridged Version." Healthcare Policy 3(3): 54-63.

Morgan, S.G., J.R. Daw and M.R. Law. 2013a. Rethinking Pharmacare in Canada, C.D. Howe Institute Commentary. Toronto, ON: C.D. Howe Institute.

Morgan, S.G., J.R. Daw and P.A. Thomson. 2013b. "International Best Practices for Negotiating

'Reimbursement Contracts' with Price Rebates from Pharmaceutical Companies." Health Affairs 32(4): 771-77. doi:10.1377/hlthaff.2012.1268.

Morgan, S.G., G. Hanley, M. McMahon and M.L. Barer. 2007. “Influencing Drug Prices through FormularyBased Policies: Lessons from New Zealand." Healthcare Policy 3(1): 121-40.

Morgan, S.G., J. Hunt, J. Rioux, J. Proulx, D. Weymann and C. Tannenbaum. (In Press). “Frequency and Cost of Potentially Inappropriate Prescriptions for Older Adults: An Analysis of 9 Provincial Drug Plan Claims." Canadian Medical Association Journal Open.

Morgan, S.G., J. Kennedy, K. Boothe, M. McMahon, E. Roughead and D. Watson. 2009. “Toward an Understanding of High Performance Pharmaceutical Policy Systems: A 'Triple-A' Framework and Example Analysis." The Open Health and Policy Journal 2: 1-9.

Morgan, S.G., M. Law, J. R. Daw, L. Abraham and D. Martin. 2015. “Estimated Cost of Universal Public Coverage of Prescription Drugs in Canada." Canadian Medical Association Journal 187(7): 491-97. doi:10.1503/ cmaj.141564. 
Morgan, S.G., D. Martin, M.-A. Gagnon, B. Mintzes, J.R. Daw and J. Lexchin. 2015. Pharmacare 2020: The Future of Drug Coverage in Canada (pp. 23). Vancouver: Pharmaceutical Policy Research Collaboration.

Morgan, S.G., K. Smolina, D. Mooney, C.B. Raymond, M. Bowen, C. Gorczynski and K. Rutherford. 2013. The Canadian Rx Atlas, 3rd Edition. Vancouver: UBC Centre for Health Services and Policy Research.

NPS MedicineWise. 2015. Foundations for a MedicineWise Tomorrow: Annual Report 2015. Strawberry Hills, Australia: NPS MedicineWise.

O’Brady, S., M.-A. Gagnon and A. Cassels. 2015. "Reforming Private Drug Coverage in Canada: Inefficient Drug Benefit Design and the Barriers to Change in Unionized Settings." Health Policy 119(2): 224-31. doi:10.1016/j.healthpol.2014.11.013.

Organisation for Economic Co-operation and Development (OECD). 2012. Structural Analysis (STAN) Databases: RED expenditures by Industry. Retrieved February 17, 2013. <http://stats.oecd.org/>.

Organisation for Economic Co-operation and Development (OECD). 2014. OECD Health Statistics 2014 - Frequently Requested Data. Retrieved July 31, 2014. <http://www.oecd.org/health/health-systems/oecdhealth-statistics-2014-frequently-requested-data.htm>.

Osborn, R., D. Moulds, D. Squires, M.M. Doty and C. Anderson. 2014. International Survey of Older Adults Finds Shortcomings in Access, Coordination, and Patient-Centered Care. New York: The Commonwealth Fund.

PMPRB. 2014. Patented Medicine Prices Review Board: Annual Report 2013. Ottawa: Patented Medicine Prices Review Board.

Renwick, M.J., K. Smolina, E.J. Gladstone, D. Weymann and S.G. Morgan. 2016. “Postmarket Policy Considerations for Biosimilar Oncology Drugs." The Lancet Oncology 17(1): e31-38.

Rochon, P.A., M. Sekeres, J. Lexchin, D. Moher, W. Wu, S.R. Kalkar et al. 2010. “Institutional Financial Conflicts of Interest Policies at Canadian Academic Health Science Centres: A National Survey." Open Medicine 4(3): e134-38.

Samoy, L.J., P.J. Zed, K. Wilbur, R.M. Balen, R.B. Abu-Laban and M. Roberts. 2006. “Drug-Related Hospitalizations in a Tertiary Care Internal Medicine Service of a Canadian Hospital: A Prospective Study." Pharmacotherapy: The Journal of Human Pharmacology and Drug Therapy 26(11): 1578-86. doi:10.1592/ phco.26.11.1578.

Schoen, C., R. Osborn, D. Squires, M. Doty, P. Rasmussen, R. Pierson and S. Applebaum. 2012. "A Survey of Primary Care Doctors in Ten Countries Shows Progress in Use of Health Information Technology, Less in Other Areas." Health Affairs 31(12): 2805-16. doi:10.1377/hlthaff.2012.0884.

Seiter, A. 2010. A Practical Approach to Pharmaceutical Policy. Washington, D.C.: World Bank.

Shnier, A., J. Lexchin, B. Mintzes, A. Jutel and K. Holloway. 2013, “Too Few, Too Weak: Conflict of Interest Policies at Canadian Medical Schools." PLoS ONE 8(7): e68633. doi:10.1371/journal.pone.0068633.

Sketris, I.S., E.M. Langille Ingram and H.L. Lummis. 2009. "Strategic Opportunities for Effective Optimal Prescribing and Medication Management." Canadian Journal of Clinical Pharmacology 16(1): e103-25.

Smolina, K., N. Persaud and S.G. Morgan. 2016. “Toward Better Prescription Drug Surveillance in Canada.” Canadian Medial Association Journal doi:10.1503/cmaj.151120.

Spurling, G.K., P.R. Mansfield, B.D. Montgomery, J. Lexchin, J. Doust, N. Othman and A.I. Vitry. 2010. "Information from Pharmaceutical Companies and the Quality, Quantity, and Cost of Physicians' Prescribing: A Systematic Review." PLoS Medicine 7(10): e1000352. doi:10.1371/journal.pmed.1000352.

Vogler, S., L. Lepuschütz, P. Schneider and V. Stühlinger. 2015. Study on Enhanced Cross-Country Coordination in the Area of Pharmaceutical Product Pricing. Brussels, Belgium: European Commission.

"We Need Romanow's National Drug Agency." 2003. Canadian Medical Association Journal 168(3): 249-51.

World Health Organization (WHO). 1988. Guidelines for Developing National Drug Policies. Geneva, Switzerland: WHO.

World Health Organization (WHO). 2001. How to Develop and Implement a National Drug Policy, Second Edition. Geneva, Switzerland: WHO. 